\title{
Preclinical Pharmacology and Pharmacokinetics of Inhaled Hexadecyl-Treprostinil (C16TR), a Pulmonary Vasodilator Prodrug
}

\author{
Michel R. Corboz, Zhili Li, Vladimir Malinin, Adam J. Plaunt, Donna M. Konicek, \\ Franziska G. Leifer, Kuan-Ju Chen, Charles E. Laurent, Han Yin, Marzena C. Biernat, \\ Dany Salvail, Jianguo Zhuang, Fadi Xu, Aidan Curran, ${ }^{1}$ Walter R. Perkins, \\ and Richard W. Chapman
}

\begin{abstract}
Insmed Incorporated, Research \& Development, Bridgewater, New Jersey (M.R.C., Z.L., V.M., A.J.P., D.M.K., F.G.L., K.-J.C., W.R.P., R.W.C.); IPS Therapeutique Inc., Sherbrooke, Québec, Canada (C.E.L., H.Y., M.C.B., D.S.); Lovelace Respiratory Research Institute, Pathophysiology Program, Albuquerque, New Mexico (J.Z., F.X.); and Envigo CRS Inc., East Millstone, New Jersey (A.C.)
\end{abstract}

Received April 11, 2017; accepted August 14, 2017

\begin{abstract}
This article describes the preclinical pharmacology and pharmacokinetics (PK) of hexadecyl-treprostinil (C16TR), a prodrug of treprostinil (TRE), formulated in a lipid nanoparticle (LNP) for inhalation as a pulmonary vasodilator. C16TR showed no activity $(>10 \mu \mathrm{M})$ in receptor binding and enzyme inhibition assays, including binding to prostaglandin $\mathrm{E}_{2}$ receptor 2, prostaglandin $D_{2}$ receptor 1 , prostaglandin $I_{2}$ receptor, and prostaglandin $E_{2}$ receptor 4; TRE potently bound to each of these prostanoid receptors. C16TR had no effect (up to $200 \mathrm{nM}$ ) on platelet aggregation induced by ADP in rat blood. In hypoxia-challenged rats, inhaled C16TR-LNP produced dose-dependent (0.06-6 $\mu \mathrm{g} / \mathrm{kg}$ ), sustained pulmonary vasodilation over 3 hours; inhaled TRE $(6 \mu \mathrm{g} / \mathrm{kg})$ was active at earlier times but lost its effect by 3 hours. Single- and multiple-dose PK studies of inhaled
\end{abstract}

C16TR-LNP in rats showed proportionate dose-dependent increases in TRE $C_{\max }$ and area under the curve (AUC) for both plasma and lung; similar results were observed for dog plasma levels in single-dose PK studies. In both species, inhaled C16TRLNP yielded prolonged plasma TRE levels and a lower plasma TRE $C_{\max }$ compared with inhaled TRE. Inhaled C16TR-LNP was well tolerated in rats and dogs; TRE-related side effects included cough, respiratory tract irritation, and emesis and were seen only after high inhaled doses of C16TR-LNP in dogs. In guinea pigs, inhaled TRE $(30 \mu \mathrm{g} / \mathrm{ml})$ consistently produced cough, but C16TRLNP $(30 \mu \mathrm{g} / \mathrm{ml})$ elicited no effect. These results demonstrate that C16TR-LNP provides long-acting pulmonary vasodilation, is well tolerated in animal studies, and may necessitate less frequent dosing than inhaled TRE with possibly fewer side effects.

\section{Introduction}

Pulmonary arterial hypertension (PAH) is a life-threatening, progressive disease that is characterized by the constriction and remodeling of the pulmonary vasculature, leading to increased pulmonary vascular resistance and pulmonary arterial pressure (PAP), most often resulting in right-sided heart failure (Stamm

Funding was provided by Insmed Incorporated. Primary laboratory of origin: Insmed Incorporated, Bridgewater, NJ.

${ }^{1}$ Current affiliation: Pulmatrix, Lexington, Massachusetts.

https://doi.org/10.1124/jpet.117.242099. et al., 2011; Frumkin, 2012). Current therapies to treat PAH have been directed toward reversing the pulmonary vasoconstriction and, more recently, to the resolution of pulmonary vascular remodeling, which includes smooth muscle cell proliferation and partial or complete occlusion of pulmonary blood vessels. Therapies currently used for the treatment of PAH include prostanoids (Skoro-Sajer et al., 2007; Nadler and Edelman, 2010; Channick et al., 2012), endothelin receptor antagonists (Abman, 2009), phosphodiesterase type 5 inhibitors (Wilkins et al., 2008), a soluble guanylate cyclase activator (Khaybullina et al., 2014), and calcium channel blockers (Taichman et al., 2014).

ABBREVIATIONS: AUC, area under the plasma curve; C12TR, dodecyl-treprostinil; C14TR, tetradecyl-treprostinil; C16OTR, ether-linked hexadecyl-treprostinil derivative; C16TR, hexadecyl-treprostinil; $C_{\max }$, mean maximum plasma concentration; CRTH2, chemoattractant receptorhomologous molecule expressed on T-helper cells; DOPC, 1,2-dioleoyl-sn-glycero-3-phosphocholine; $\mathrm{DP}_{1}$, prostaglandin $\mathrm{D}_{2}$ receptor 1 ; $\mathrm{DSPE}_{\text {- }}$ PEG2000, 1,2-distearoyl-sn-glycero-3-phosphoethanolamine- $\mathrm{N}$-[methoxy(polyethylene glycol)-2000; $\mathrm{EP}_{1}$, prostaglandin $\mathrm{E}_{2}$ receptor 1; $\mathrm{EP}_{2}$, prostaglandin $\mathrm{E}_{2}$ receptor 2; $\mathrm{EP}_{3}$, prostaglandin $\mathrm{E}_{2}$ receptor 3; $\mathrm{EP}_{4}$, prostaglandin $\mathrm{E}_{2}$ receptor 4; FP, prostaglandin $\mathrm{F} 2 \alpha$ receptor; HPLC/MS/MS, high-performance liquid chromatography/mass spectrometry; HPLC/UV, high-performance liquid chromatography/ultraviolet; HR, heart rate; INS1009, hexadecyl-treprostinil formulated in a lipid nanoparticle; IP, prostaglandin $\mathrm{I}_{2}$ receptor; $\mathrm{K}_{2}$-EDTA, Di-potassium ethylenediaminetetraacetic acid; LLOQ, lower limit of quantitation; LNP, lipid nanoparticle; PAH, pulmonary arterial hypertension; PAP, pulmonary arterial pressure; PBS, phosphate-buffered saline; $\mathrm{PK}$, pharmacokinetics; $\mathrm{SaO}_{2}$, arterial oxygen saturation; $\mathrm{SAP}$, systemic arterial blood pressure; $T_{\text {max }}$, time to maximum plasma concentration; TRE, treprostinil. 
Treprostinil (TRE) is a relatively stable analog of prostacyclin that has a longer plasma half-life than early prostacyclin agonists such as iloprost (Ventavis) and epoprostenol (Flolan/Veletri). TRE has therapeutic benefit when given by continuous infusion (Remodulin), oral (Orenitram) and inhaled (Tyvaso) routes of administration. Remodulin administration is associated with significant injection site pain (s.c.) or concern of infection (i.v. administration) (Simonneau et al., 2002; Remodulin, 2014); however, Orenitram and Tyvaso require multiple doses daily, and efficacy may not be fully maintained over a 24-hour period (Channick et al., 2012; Tyvaso, 2013; Orenitram, 2014; Feldman et al., 2015). Inhaled TRE is also associated with numerous adverse side effects, which limits the dose. For example, cough, headache, laryngeal irritation, emesis, flushing, nausea, and hypotension are the side effects most frequently found with Tyvaso, which is taken four times daily (Voswinckel et al., 2006; Nadler and Edelman, 2010; Channick et al., 2012; Tyvaso, 2013).

Sandifer et al. (2005) demonstrated that continuously inhaled TRE showed greater efficacy in sheep with fewer systemic side effects than continuously infused drug; however, in that study, inhaled TRE had to be administered continuously to maintain a consistent effect. This, of course, is impractical for patients. We reasoned that an inhaled slow-release formulation of drug might achieve long-acting pulmonary vasodilation and elicit fewer systemic side effects. To accomplish this, a series of ester-linked prodrugs of TRE formulated in a lipid nanoparticle (LNP) and optimized for delivery by inhalation were developed (Leifer et al., 2017, unpublished). The culmination of this research identified hexadecyl-treprostinil (C16TR) as a lead inhalation prodrug candidate.

Here we describe the preclinical pharmacology and pharmacokinetic (PK) properties of the C16TR prodrug formulated in a LNP for inhalation. Some of these results have appeared in abstracts and posters at the American Thoracic Society and European Respiratory Society (Leifer et al., 2014; Malinin et al., 2014, 2015, 2017; Chapman et al., 2015, 2017; Li et al., 2016). The experiments performed and described herein are the following: 1) in vitro assays on human prostanoid receptor binding, 2) platelet aggregation evaluations in rat blood, 3) in vivo activity in a rat model of acute hypoxia-induced pulmonary hypertension, 4) PK in rats and dogs, and 5) assessment on the cough reflex in guinea pigs.

\section{Materials and Methods}

Materials. We obtained TRE from Chirogate International (Taoyuan County, Taiwan, Republic of China) and dodecanol, tetradecanol, hexadecanol, 1,4 dioxane, amberlyst-15 resin, and squalane from Sigma (St. Louis, MO); 1,2-distearoyl-sn-glycero-3-phosphoethanolamine-N-[methoxy(polyethylene glycol)-2000] (DSPE-PEG2000, ammonium salt) and cholesterol-PEG2000 were obtained from NOF America (White Plains, NY). Dodecyl-TRE (C12TR), tetradecyl-TRE (C14TR), and C16TR were synthesized at Insmed Incorporated (Bridgewater, NJ) via esterification of TRE acid in the presence of long-chain alcohols catalyzed by the acidic resin amberlyst-15 as described previously (Leifer et al., 2017, unpublished). Phosphatebuffered saline (PBS) was acquired from Mediatech (Manassas, VA).

LNP Prodrug Formulations. Two different LNP prodrug formulations of C16TR were used. One formulation contains C16TR and the excipients squalane and DSPE-PEG2000 at a molar ratio of 45: 45:10, suspended in PBS. This formulation has previously been termed INS1009 (Chapman et al., 2015, 2017; Malinin et al., 2015, 2017; Han et al., 2016 a,b; Li et al., 2016). The other formulation contains C16TR and squalane, but with 1,2-dioleoyl-sn-glycero-3phosphocholine (DOPC) and cholesterol-PEG2000; the molar ratio of these four ingredients was 40:40:10:10. This formulation has been previously termed T623 (Leifer et al., 2014, 2017; Malinin et al., 2014). Two additional TRE prodrugs were evaluated in dogs and consisted of C14TR or C12TR, which were formulated in LNP containing squalane, DOPC, and cholesterol-PEG2000 in the ratio of 40:40:10:10. Nanoparticles were suspended in PBS and exhibited mean diameters ranging from 100 to $150 \mathrm{~nm}$ as measured by dynamic light scattering. An ether-linked derivative of hexadecyltreprostinil (C16OTR) was also used that incorporates an ether bond linking the TRE moiety to the hexadecyl group; this compound was formulated in LNPs as C16OTR/squalane/DSPEPEG2000 in a molar ratio of 45:45:10. The chemical structures of C16TR and C16OTR are shown in Fig. 1.

Radioligand Binding Assays. Radioligand binding assays for human prostaglandin $\mathrm{D}_{2}$ receptor $1\left(\mathrm{DP}_{1}\right)$, prostaglandin $\mathrm{I}_{2}$ receptor (IP), prostaglandin $\mathrm{E}_{2}$ receptor $1\left(\mathrm{EP}_{1}\right)$, prostaglandin $\mathrm{E}_{2}$ receptor $2\left(\mathrm{EP}_{2}\right)$, prostaglandin $\mathrm{E}_{2}$ receptor $3\left(\mathrm{EP}_{3}\right)$, prostaglandin $\mathrm{E}_{2}$ receptor $4\left(\mathrm{EP}_{4}\right)$, prostaglandin $\mathrm{F} 2 \alpha$ receptor (FP), and chemoattractant receptor homologous molecule expressed on T-helper cells $\left(\mathrm{CRTH}_{2}\right)$ receptors were performed by Eurofins Panlabs (Taipei, Taiwan, Republic of China). The following radioligands were used: $\left[{ }^{3} \mathrm{H}\right]$ prostaglandin $\mathrm{D}_{2}\left(\mathrm{DP}_{1}\right.$, $\left.\mathrm{CRTH}_{2}\right),\left[{ }^{3} \mathrm{H}\right]$ prostaglandin $\mathrm{E}_{2}\left(\mathrm{EP}_{1}, \mathrm{EP}_{2}, \mathrm{EP}_{3}, \mathrm{EP}_{4}\right),\left[{ }^{3} \mathrm{H}\right]$ prostaglandin $\mathrm{F} 2{ }_{\alpha}(\mathrm{FP})$, and $\left[{ }^{3} \mathrm{H}\right]$ iloprost (IP). The compounds were incubated at $25^{\circ} \mathrm{C}$ for either 1 hour $\left(\mathrm{EP}_{1}, \mathrm{FP}\right.$, and IP) or 2 hours $\left(\mathrm{DP}_{1}, \mathrm{CRTH}_{2}, \mathrm{EP}_{2}, \mathrm{EP}_{3}\right.$ and $\mathrm{EP}_{4}$ ) with human recombinant Chinese hamster ovary $\mathrm{K} 1$ cell line cells expressing the appropriate human prostanoid receptor. Binding activity was measured as the inhibition (\%) of radioligand binding, and $\mathrm{IC}_{50}$ values were determined by a nonlinear least squares regression analysis using MathIQ (ID Business Solutions Ltd, Guildford, UK). Because C16TR itself is insoluble in water, a micelle formulation containing C16TR and DSPE-PEG2000 in a 70:30 molar ratio was used to facilitate the availability of the prodrug in this assay.

Platelet Aggregation. Blood samples from male Sprague Dawley rats (Charles River Laboratories, QC, Canada) were centrifuged to extract platelet-rich plasma and platelet-poor plasma. Platelet-rich plasma was diluted with platelet-poor plasma to yield samples
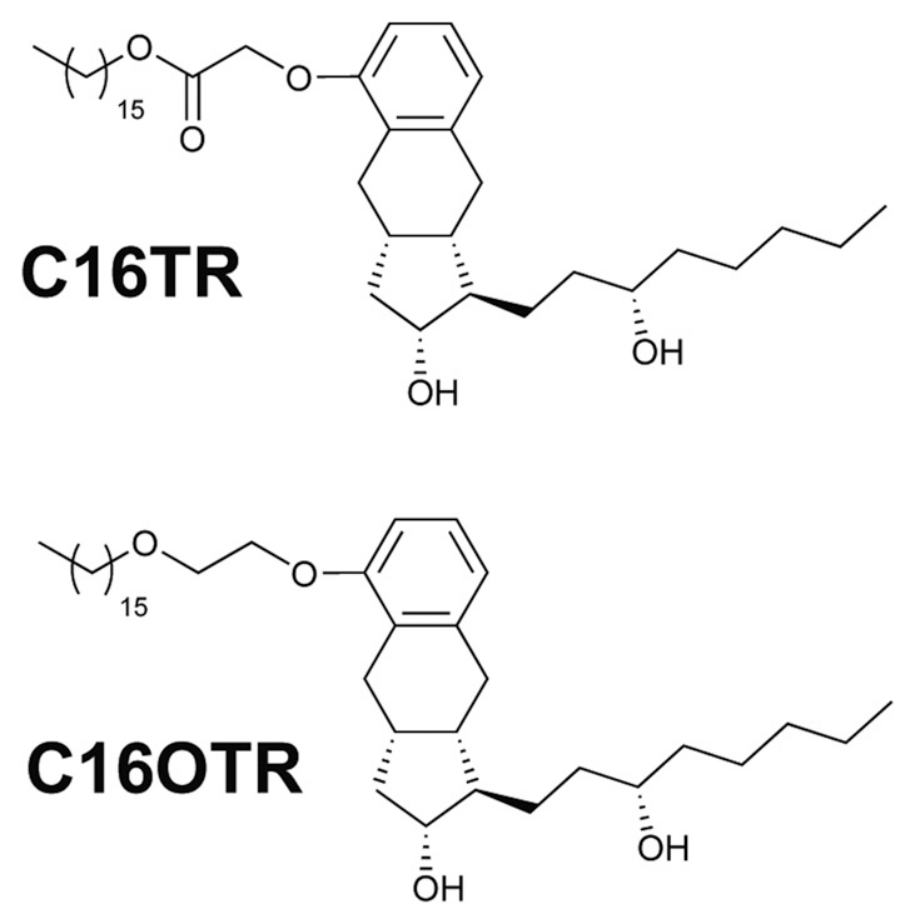

Fig. 1. Chemical structures of C16TR and C16OTR. 
containing $3.5 \times 10^{8}$ platelets $/ \mathrm{ml}$. Platelet aggregation was induced by the addition of $\mathrm{ADP}(10 \mu \mathrm{M}$ final concentration) measured with a Chrono-log aggregometer. Test concentrations for C16TR formulated in squalane/DOPC/cholesterol-PEG2000 lipid nanoparticles were 50, 100,200 , and $400 \mathrm{nM}$ (TRE equivalents). Values for platelet aggregation in the presence of C16TR-formulated LNP, the LNP vehicle alone, and TRE were normalized to values obtained in the presence of PBS, and the results were expressed as the percentage of inhibition attributable to drug or control.

Hypoxia Challenge in Rats. Male Sprague Dawley rats (Charles River Laboratories, Quebec, Canada) ranging in weight from 300 to $350 \mathrm{~g}$ were anesthetized with $3 \%$ isoflurane-oxygen and then transitioned to i.v. ketamine/xylazine (mixture of 10 and $1 \mathrm{mg} / \mathrm{ml}$, respectively, at an infusion rate of $0.02 \mathrm{ml} / \mathrm{min}$ ). The rats were prepared with tracheal, pulmonary arterial and arterial blood pressure catheters; systemic arterial blood pressure (SAP), heart rate (HR) and PAP were measured throughout the study. A pulse oximeter was placed on the paw to measure arterial oxygen saturation $\left(\mathrm{SaO}_{2}\right)$. The rats were artificially ventilated, and drugs were delivered using an Aeroneb Pro nebulizer (Aerogen, Galway, Ireland) that was interposed into the inspiratory line of the ventilator. The volume of test article nebulized was fixed at $300 \mu \mathrm{l}$, and doses were varied by altering the drug concentration.

After measurement of $\mathrm{PAP}, \mathrm{SAP}, \mathrm{HR}$, and $\mathrm{SaO}_{2}$ during ventilation on room air $\left(21 \% \mathrm{O}_{2}\right)$, the inspired gas was switched to a hypoxic gas mixture $\left(10 \% \mathrm{O}_{2}\right)$ and maintained at hypoxic levels $\left(\mathrm{SaO}_{2} \approx 45 \%-60 \%\right)$ for the duration of the study. Once a 5-minute stable elevation in PAP had been achieved during the hypoxia exposure, physiologic parameters, including PAP, were measured to represent their hypoxic baseline values. The following test articles [PBS, TRE, C16TR formulated in squalane/DSPE-PEG2000 LNP $(0.06-6 \mu \mathrm{g} / \mathrm{kg})$, and C16OTR formulated in the same LNP formulation to C16TR $(6 \mu \mathrm{g} / \mathrm{kg})]$ were nebulized, delivered directly into the tracheal tube, and physiologic parameters were measured over a 180 -minute period. The data were sampled over 20 -second periods ( 200 data points per second) and averaged as a single value at times of $0-5,5.3-20,20.3-60,60.3-100$, 100.3-147, and 147.7-180 minutes after nebulization of the drugs. The changes induced by the test articles were measured at each of these time intervals and expressed as a percentage of reduction of the hypoxic baseline value. A single dose of test article was given per rat. In studies involving inhaled C16TR-LNP $(6 \mu \mathrm{g} / \mathrm{kg})$ and TRE $(6 \mu \mathrm{g} / \mathrm{kg})$, blood samples $(0.2 \mathrm{ml} / \mathrm{sample})$ were collected at times of $3,20,40,60$, 90 , and 180 minutes after drugs, and lungs were harvested at the end of the studies (i.e., 180 minutes). The concentration of TRE and C16TR in the plasma and lung were measured by high-performance liquid chromatography/mass spectrometry (HPLC/MS/MS). Statistical significance differences between the treatment groups were determined using a one way analysis of variance followed by a Tukey's multiple comparison test.

Pharmacokinetics in Rats. Male Sprague Dawley rats (Charles River Laboratories) ranging in weight from 300 to $350 \mathrm{~g}$ were placed in a 12-port rodent nose-only inhalation tower (CH Technologies, Westwood, NJ) for the exposure to inhaled drugs. The total airflow through the tower was maintained at 6 liters $/ \mathrm{min}$, and a glass filter was connected to one of the exposure ports to measure the aerosol drug concentration. Drug samples were collected on the filter for 5 minutes at a vacuum flow of 0.5 liters/min and measured by high-performance liquid chromatography/ultraviolet (HPLC/UV). The inhaled pulmonary dose $(\mu \mathrm{g} / \mathrm{kg})$ of C16TR was derived from the relationship of aerosol drug concentration in the nose-only inhalation tower, the duration of exposure to the test articles, minute ventilation based on body weight, and a $10 \%$ deposition factor as described previously (Wolff and Dorato, 1993; Alexander et al., 2008). Values for C16TR were converted (0.635) to molar equivalents of TRE based on the molecular weights of C16TR (mol. wt. = 614.9) and TRE (mol. wt. = 390.5).

A single-dose PK study was performed with C16TR formulated in squalane, DOPC, cholesterol-PEG2000 (40:40:10:10). Evaluations were performed with inhaled pulmonary doses of $0.6,1.8,6$, and
$18 \mu \mathrm{g} / \mathrm{kg}$. Blood and lung tissue samples were obtained in three rats/time point at each time point of $1,2,3,6,12,20$, and 24 hours after the start of the drug exposure. A repeat-dose PK study was also performed using C16TR formulated in squalane, DSPE-PEG2000. In this experiment, cohorts of four rats/dose were exposed for 1 , 7, or 14 consecutive days, and evaluations were performed with inhaled pulmonary doses of $0.6,1.8,6$, and $18 \mu \mathrm{g} / \mathrm{kg}$. Blood samples were obtained from each rat at $1,3,6$, and 24 hours after the start of the drug exposure, and lungs were harvested at the end of the study (i.e., 24 hours after the final drug dose). For all PK studies, the blood samples were placed on ice until centrifugation to extract the plasma. Both the plasma and lung samples were stored at $-50^{\circ} \mathrm{C}$ before analysis of their TRE and C16TR concentrations using HPLC/MS/MS.

The following calculations were performed on the plasma TRE data: mean maximum plasma concentration $\left(C_{\max }, \mathrm{ng} / \mathrm{ml}\right)$, time to maximum plasma concentration $\left(T_{\max }, \min \right)$, and area under the plasma TRE concentration curve over a 24 -hour period $\left(\mathrm{AUC}_{0-24 \mathrm{~h}}, \mathrm{ng} * \mathrm{~h} / \mathrm{ml}\right)$ measured by the trapezoidal method (Chow and Liu, 2007). For lung tissue, the concentration of both C16TR and TRE was measured in lung homogenate and converted to the total equivalent concentration of TRE. Results were expressed as the TRE equivalent content per gram of lung tissue (nanograms per gram).

Pharmacokinetics in Dogs. Experiments were performed on six male and six female beagle dogs (Marshall BioResources, North Rose, $\mathrm{NY}$ ). The dogs were anesthetized with propofol $(7 \mathrm{mg} / \mathrm{kg}$, i.v.), intubated with a cuffed endotracheal tube and mechanically ventilated on room air at a tidal volume of $10 \mathrm{ml} / \mathrm{kg}$ and $15 \mathrm{breaths} / \mathrm{min}$. A dosimetry system similar to that previously described for use in dogs (Kuehl et al., 2010) was used to deliver inhaled TRE and the LNP formulations (squalane, DOPC, cholesterol-PEG2000) of C12TR, C14TR, and C16TR. The compounds were nebulized with an Aeroneb Laboratory nebulizer (Aerogen) and delivered directly into a 500-ml expansion chamber on the inspiratory limb of the ventilator. The power interrupter on the nebulizer was set to 1 second on and 2 seconds off to minimize condensation of nebulized material on the inner walls of the system. The concentration of inhaled drug was measured by collecting drug deposited on a filter attached to the end of the endotracheal tube per unit of time. Inhaled drug dose (micrograms per kilograms) was measured from the relationships of aerosol drug concentration, the duration of drug exposure, and minute ventilation based on body weight as described previously (Alexander et al., 2008).

At the end of the drug delivery, the anesthesia infusion was discontinued and the dogs were weaned off the ventilator. After full recovery from the anesthesia, which took only a few minutes, the dogs were returned to their home cages. The dogs were checked for clinical signs for up to 3 days after dosing with the drugs. Blood collections were performed at times of $0.02,0.08,0.16,0.50,1,2,4,8,12,16,20,24,48$, and 72 hours after drug administration with approximately $2 \mathrm{ml} /$ sample of blood taken at each time point ( $28 \mathrm{ml}$ blood total). The blood samples were collected into tubes containing di-potassium ethylenediaminetetraacetic acid $\left(\mathrm{K}_{2}\right.$-EDTA) anticoagulant and put immediately on ice until processed. Processing occurred within 2 hours of blood collection. The samples were centrifuged (for 10 minutes at approximately $2000 \mathrm{~g}$ at 2 to $8^{\circ} \mathrm{C}$ ) to obtain plasma. Plasma (approximately $500 \mu \mathrm{l}$ for each aliquot) was stored frozen at nominal $-80^{\circ} \mathrm{C}\left( \pm 10^{\circ} \mathrm{C}\right)$, and the concentration of TRE was measured using a qualified HPLC/MS/MS method. The plasma TRE samples were used to determine $C_{\max }, T_{\max }$, and AUC $0-24 \mathrm{~h} / 0-72 \mathrm{~h}$.

Measurement of TRE and C16TR in Blood Plasma and Lung Homogenate. TRE and C16TR were measured in plasma and lung homogenate samples by HPLC/MS/MS assays. The TRE assay had a lower limit of quantitation (LLOQ) of $25 \mathrm{pg} / \mathrm{ml}$ for TRE in plasma and $250 \mathrm{pg} / \mathrm{ml}$ in lung homogenate. The C16TR assay had an LLOQ of $300 \mathrm{pg} / \mathrm{ml}$ in lung homogenate.

TRE and C16TR were extracted from plasma and lung homogenate samples by liquid extraction in acetonitrile/water/acetic acid (50:50: $0.5, \mathrm{v} / \mathrm{v} / \mathrm{v})$. 1-Naphthoxyacetic acid was used as an internal standard 
for TRE, and decyl-TRE or C14TR was used as internal standard for C16TR. Extracts were analyzed using Ace 3 C18 (Kinetex phenylhexyl) reverse-phase analytical column at a flow rate of $1 \mathrm{ml} / \mathrm{min}$ with an injection volume of $20 \mu \mathrm{l}$. The gradient method was used with mobile phase A prepared as 1\% formic acid in water and mobile phase $\mathrm{B}$ as $100 \%$ acetonitrile. The starting concentration of mobile phase $\mathrm{B}$ in a gradient was $35 \%$. Detection was done by HPLC/MS/MS (AB SCIEX, Framingham, MA).

Cough Reflex in Guinea Pigs. Cough was measured in conscious, unrestrained guinea pigs (250-350 g) (Charles River Laboratories Inc., Wilmington, MA) by three established criteria (Morice et al., 2007): changes in ventilation using a whole-body plethysmograph, cough sounds measured with a microphone, and visual inspection of the postural changes during cough. The guinea pigs were exposed to nebulized PBS $(n=6)$, TRE at nebulizer concentrations of $1(n=1), 3.3(n=3), 10(n=4), 30(n=7)$, and C16TR-LNP at a concentration of $30 \mu \mathrm{g} / \mathrm{ml}$ (TRE equivalent) $(n=6)$. A guinea pig exposed to TRE at $300 \mu \mathrm{g} / \mathrm{ml}$ experienced adverse effects and dosing was discontinued after 4 minutes. The compounds were given directly into the whole-body plethysmograph using an Ultra-Neb Pro nebulizer (nebulizer output of $0.36 \mathrm{ml} / \mathrm{min}$ ) for 10 minutes, and the total number of coughs was measured during the 10 minutes of nebulization and for an additional 20-minute period after the test article was given. Airflow through the plethysmograph was maintained at a constant flow rate of 2 liters/min and was derived from a compressed air source. Statistical significance between the treatment groups was determined using Kruskal-Wallis analysis of variance (nonparametric) followed by the Dunn method for joint ranking (Kruskal and Wallis, 1952; Dunn, 1961).

Animal Care and Use. The experimental protocols involving animals were approved by the Institutional Animal Care and Use Committees at the following institutions: IPS Therapeutique Inc., Sherbrooke, QC, Canada; Lovelace Respiratory Research Institute, Albuquerque, New Mexico; and Envigo CRS Inc., East Millstone, NJ. These institutions are facilities accredited by the Association for the Assessment and Accreditation of Laboratory Animal Care International.

\section{Results}

Binding to Prostanoid Receptors. TRE had binding to the following prostanoid receptors with an order of potency (estimated $\left.\mathrm{IC}_{50}\right)$ of $\mathrm{EP}_{2}[0.014 \mu \mathrm{M})>\mathrm{DP}_{1}(0.023 \mu \mathrm{M})>\mathrm{IP}$ $(0.079 \mu \mathrm{M})>\mathrm{EP}_{1}(0.20 \mu \mathrm{M})>\mathrm{EP}_{3}(0.25 \mu \mathrm{M})>\mathrm{EP}_{4}(0.92$ $\mu \mathrm{M})$ ]; TRE had no activity $(>10 \mu \mathrm{M})$ against $\mathrm{CRTH}_{2}$ and FP (Table 1). In contrast, C16TR had no binding $(>10 \mu \mathrm{M})$ to $\mathrm{EP}_{2}$, $\mathrm{DP}_{1}, \mathrm{IP}$, and $\mathrm{EP}_{4}$ receptors; evaluations were not performed against the other prostanoid receptors. Similar results were found with C16OTR, which had no binding $(>10 \mu \mathrm{M})$ to these prostanoid receptors.

TABLE 1

Binding activity of TRE and C16TR to prostanoid receptors Values are mean from duplicate experiments.

\begin{tabular}{ccc}
\hline & \multicolumn{2}{c}{ Inhibitory Concentration $\left(\mathrm{IC}_{50}, \mu \mathrm{M}\right)$} \\
\cline { 2 - 3 } Prostanoid Receptor & $\mathrm{TRE}$ & $\mathrm{C} 16 \mathrm{TR}$ \\
\hline $\mathrm{EP}_{2}$ & 0.014 & $>10$ \\
$\mathrm{DP}_{1}$ & 0.023 & $>10$ \\
$\mathrm{IP}$ & 0.079 & $>10$ \\
$\mathrm{EP}_{1}$ & 0.20 & $\mathrm{NT}$ \\
$\mathrm{EP}_{3}$ & 0.25 & $\mathrm{NT}$ \\
$\mathrm{EP}_{4}$ & 0.92 & $>10$ \\
$\mathrm{CRTH}$ & $>10$ & $\mathrm{NT}$ \\
$\mathrm{FP}$ & $>10$ & $\mathrm{NT}$ \\
\hline
\end{tabular}

NT, Not tested.

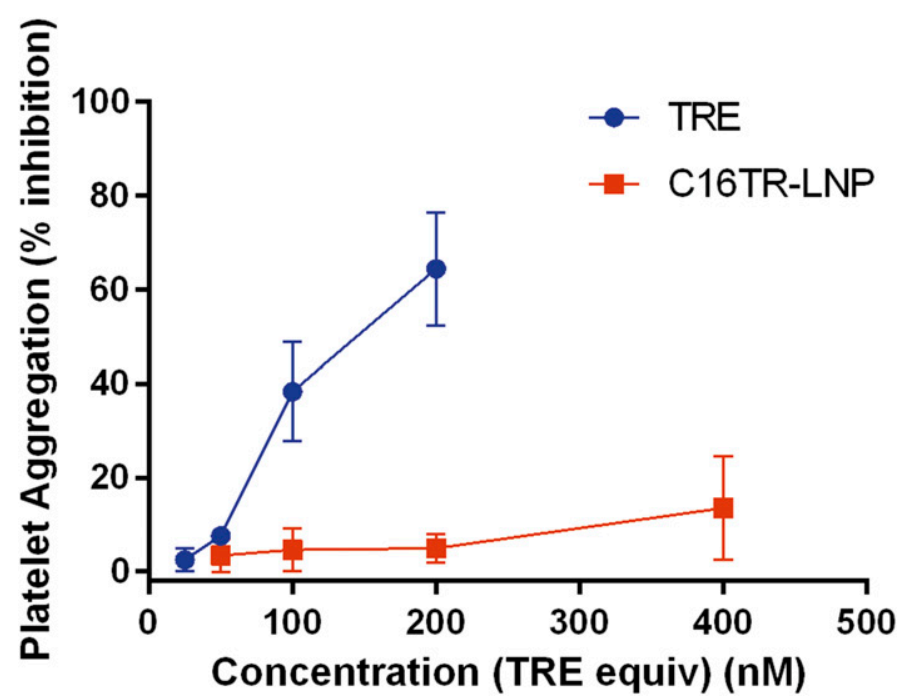

Fig. 2. Effect of C16TR formulated in squalane/DSPE-PEG2000 LNP and TRE on platelet aggregation induced by the addition of $\mathrm{ADP}(10 \mu \mathrm{M})$ to rat blood. Results are expressed as the percent inhibition of platelet aggregation from drug relative to values obtained in PBS controls. Values represent the mean \pm S.E.M. from two to three determinations.

Platelet Aggregation. TRE inhibited platelet aggregation in a concentration-dependent manner at $\geq 50 \mathrm{nM}$, with a mean maximum effect of $64 \%$. C16TR formulated in a LNP was inactive at $200 \mathrm{nM}$, with only $13.5 \%$ inhibition at $400 \mathrm{nM}$ (Fig. 2). The LNP vehicle minus C16TR had no effect (data not shown).

Hypoxia Challenge in Rats. After challenge with hypoxia, PAP increased from values of $17.8 \pm 0.6 \mathrm{~mm} \mathrm{Hg}$ during normoxia to $23.2 \pm 0.8 \mathrm{~mm} \mathrm{Hg}$ during hypoxia $(n=32)$. This elevation in PAP did not appreciably change during the 180 minutes of hypoxia exposure and was unaffected by exposure to nebulized PBS (Fig. 3). Exposure of hypoxiachallenged rats to C16TR-LNP dose dependently $(0.6-6 \mu \mathrm{g} / \mathrm{kg})$ reduced PAP; a lower dose of $0.06 \mu \mathrm{g} / \mathrm{kg}$ was inactive $(n=3)$. At the highest dose of C16TR-LNP $(6 \mu \mathrm{g} / \mathrm{kg})$, the PAP was

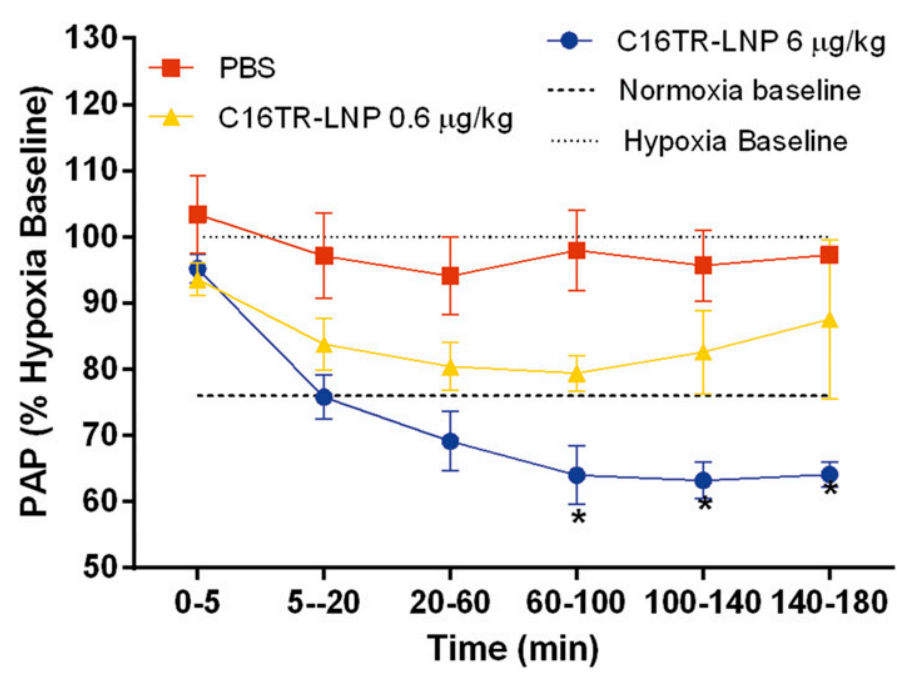

Fig. 3. Dose-response pulmonary vasodilation with inhaled C16TR formulated in squalane/DSPE-PEG2000 LNP in hypoxia-challenged rats. Targeted pulmonary doses are shown for each group. Values represent the mean \pm S.E.M. percent decrease from the hypoxic baseline $(n=3$ to 4 per dose of C16TR-LNP, $n=10$ for PBS). $* P<0.05$ compared C16TR-LNP with PBS. 
reduced to $13 \pm 1 \mathrm{~mm} \mathrm{Hg}$, which is slightly below the normoxic levels. Dose-response studies with inhaled TRE $(0.006-6 \mu \mathrm{g} / \mathrm{kg})$ in hypoxic rats also reduced PAP (data not shown), with maximum effects observed at a dose of $6 \mu \mathrm{g} / \mathrm{kg}$ (Fig. 4). A higher dose of TRE $(10 \mu \mathrm{g} / \mathrm{kg}, n=4)$ produced no further reduction in PAP (normoxia, $\mathrm{PAP}=18.6 \pm 1.6 \mathrm{~mm} \mathrm{Hg}$; hypoxia, $\mathrm{PAP}=25.1 \pm 2.6 \mathrm{~mm} \mathrm{Hg}$; hypoxia $+\mathrm{TRE}, \mathrm{PAP}=$ $18.0 \pm 1.8 \mathrm{~mm} \mathrm{Hg}$ ). No changes in SAP and HR were noted with any treatments (data not shown).

Two important differences were seen in the pulmonary vasodilator responses of inhaled C16TR-LNP and inhaled TRE (Fig. 4). First, a reduction in PAP occurred during nebulization with inhaled TRE $(6 \mu \mathrm{g} / \mathrm{kg})$ and was already $15 \%$ below the baseline values by 5 minutes after challenge, whereas the reduction in PAP for inhaled C16TR-LNP $(6 \mu \mathrm{g} / \mathrm{kg})$ was delayed and not observed until 5-20 minutes after administration (Fig. 4). Second, over 180 minutes, the reduction in PAP with inhaled TRE ( $6 \mu \mathrm{g} / \mathrm{kg})$ trended back to the hypoxic baseline values, whereas a sustained and significant reduction in PAP (relative to TRE) was seen with inhaled C16TR-LNP (6 $\mu \mathrm{g} / \mathrm{kg})$ (Fig. 4). Inhaled LNP formulated C16OTR (6 $\mu \mathrm{g} / \mathrm{kg})$, the ether-linked C16TR compound, had no effect. PAP measurements could not be reliably obtained beyond 180 minutes in this model of hypoxia-challenged rats.

Plasma concentrations of TRE were highest $(3.44 \mathrm{ng} / \mathrm{ml})$ by 3 minutes for inhaled TRE ( $6 \mu \mathrm{g} / \mathrm{kg})$ (Table 2$)$. In contrast, the plasma TRE level for inhaled C16TR-LNP $(6 \mu \mathrm{g} / \mathrm{kg})$ was only $0.06 \mathrm{ng} / \mathrm{ml}$ at 3 minutes and slowly increased to the highest value of $0.22 \mathrm{ng} / \mathrm{ml}$ at 180 minutes (Table 2). In the lung, the TRE-equivalent concentration (C16TR + TRE; see Materials and Methods) was 67-fold higher for inhaled C16TR-LNP (438 ng/g lung tissue) than for inhaled TRE (6.5 ng/g lung tissue). No TRE was detected in the plasma or lungs for inhaled C16OTR.

Pharmacokinetics in Rats. Single doses of inhaled LNPformulated C16TR $(0.6-18 \mu \mathrm{g} / \mathrm{kg})$ were administered, and the concentration of TRE in the plasma increased proportionately in a dose-dependent manner (Fig. 5A). The elimination of TRE

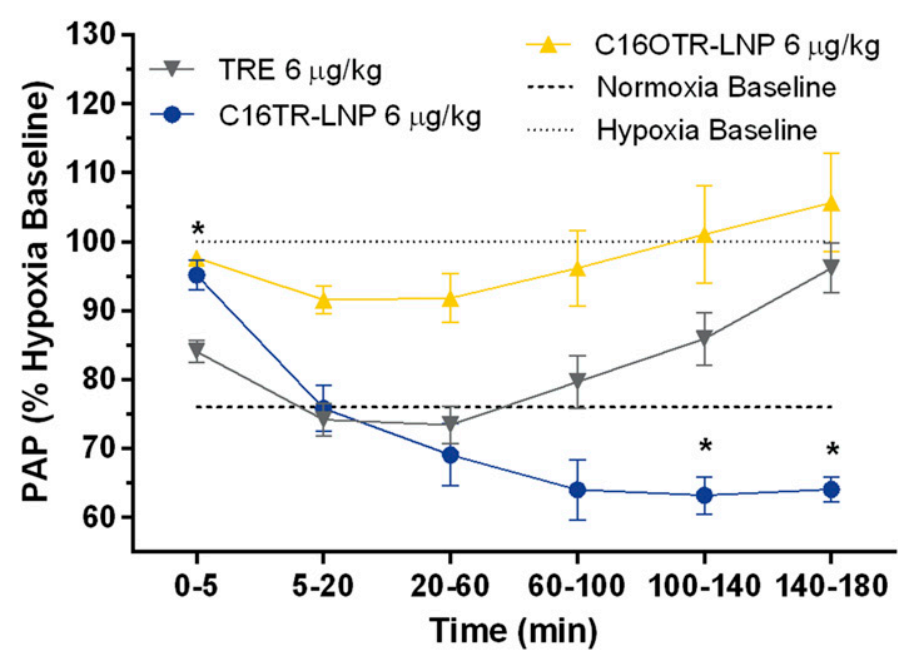

Fig. 4. Pulmonary vasodilator response to inhaled TRE and inhaled C16TR and C16OTR formulated in squalane/DSPE-PEG2000 LNP in hypoxia-challenged rats. Values represent the mean \pm S.E.M. percent decrease from the hypoxic baseline $(n=3$ for C16TR-LNP, $n=6$ for C16OTR-LNP, and $n=10$ for TRE). $* P<0.05$ compared C16TR-LNP with TRE.
TABLE 2

Plasma concentrations of TRE after inhaled TRE and inhaled C16TR formulated in squalane/DSPE-PEG2000 LNP in hypoxia-challenged rats Values are the mean plasma concentration of TRE $(\mathrm{ng} / \mathrm{ml})$.

\begin{tabular}{ccc}
\hline $\begin{array}{c}\text { Time after Start } \\
\text { of Inhalation (min) }\end{array}$ & TRE $(6 \mu \mathrm{g} / \mathrm{kg})(n=10)$ & C16TR-LNP $(6 \mu \mathrm{g} / \mathrm{kg})(n=3)$ \\
\hline 3 & 3.44 & 0.06 \\
20 & 2.07 & 0.07 \\
40 & 0.90 & 0.13 \\
60 & 0.50 & 0.14 \\
90 & 0.31 & 0.18 \\
180 & 0.44 & 0.22 \\
\hline
\end{tabular}

from the plasma followed a first-order exponential decline. There were dose-dependent $(0.6-18 \mu \mathrm{g} / \mathrm{kg})$ increases in both plasma TRE $C_{\max }$ and $\mathrm{AUC}_{0-24 \mathrm{~h}}$ for inhaled C16TR-LNP with a plasma TRE $T_{\max }$ at 1 hour at all doses (Table 3 ). The concentration of TRE and C16TR also increased in the lungs with increasing inhaled doses of C16TR-LNP (Fig. 5B), with most of the combined TRE + C16TR (TRE equivalent

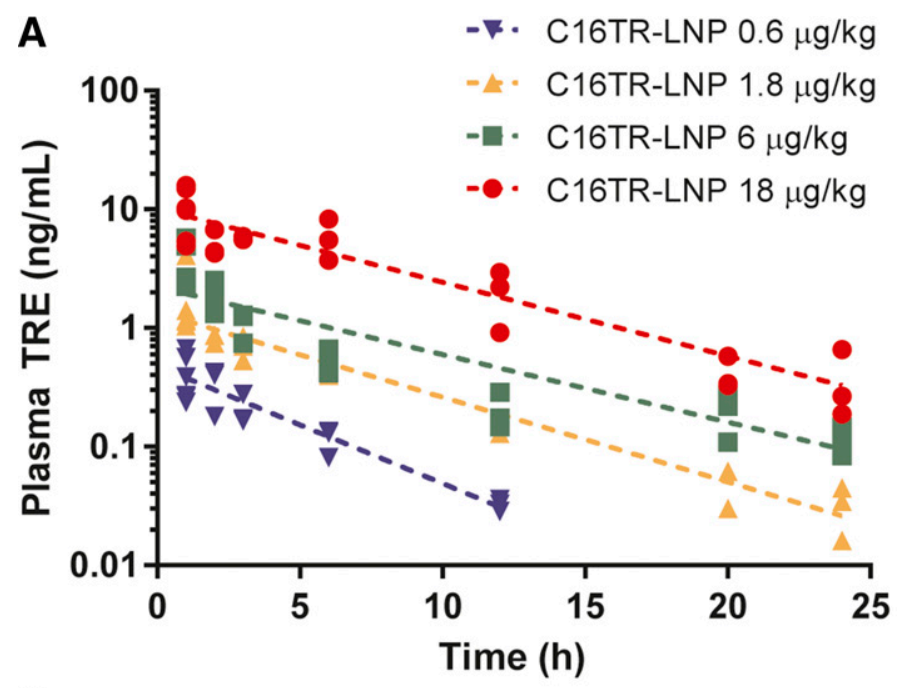

B

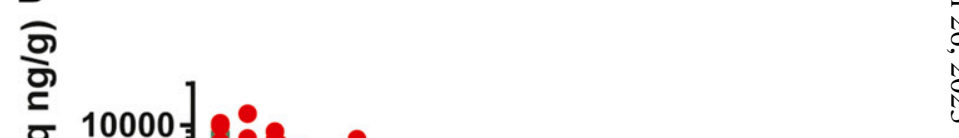

5. Concentrations of (A) TRE in the plasma and (B) combined TRE + C16TR (TRE equivalent concentration (TRE Eq)) in the lungs after noseonly inhalation of C16TR formulated in squalane/DOPC/cholesterolPEG2000 LNP in rats. Data show individual values for three rats at each of the seven time points. 
TABLE 3

TRE plasma PK in rats for inhaled C16TR formulated in squalane/DOPC/ cholesterol-PEG2000 LNP

Values are the mean $(n=21 /$ dose; three rats per time point; seven time points over 24 hours).

\begin{tabular}{|c|c|c|c|c|}
\hline \multirow{2}{*}{ Parameter } & \multicolumn{4}{|c|}{ C16TR-LNP ( $\mu \mathrm{g} / \mathrm{kg})$} \\
\hline & 0.6 & 1.8 & 6 & 18 \\
\hline TRE plasma $C_{\max }(\mathrm{ng} / \mathrm{ml})$ & 0.40 & 1.67 & 3.46 & 10.21 \\
\hline TRE plasma $T_{\max }(\mathrm{h})$ & 1 & 1 & 1 & 1 \\
\hline TRE plasma $\mathrm{AUC}_{0-24 \mathrm{~h}}(\mathrm{ng} * \mathrm{~h} / \mathrm{ml})$ & 1.89 & 7.35 & 19.61 & 70.38 \\
\hline
\end{tabular}

concentration) present as C16TR. Compared with the TRE concentration in the plasma, the lung TRE-equivalent concentration was approximately 1000-times greater.

Inhaled C16TR-LNP $(0.6-18 \mu \mathrm{g} / \mathrm{kg})$, which had been dosed daily for 14 consecutive days, was well tolerated in rats and associated with dose-proportional increases in both plasma TRE $C_{\max }$ and AUC $0-24 \mathrm{~h}$ (Table 4). No evidence of plasma TRE accumulation was seen after 14 days of dosing with inhaled C16TR-LNP, although some fluctuations of $C_{\max }$ and AUC $_{0-24 \mathrm{~h}}$ values were seen over time at the 0.6 and $6 \mu \mathrm{g} / \mathrm{kg}$ doses; however, the reason for this finding is unclear because these parameters generally remained steady over time at the other doses (Table 4). The lung concentration of TRE after repeat dosing with inhaled C16TR-LNP did not show any substantive variation over time, and there was no evidence of TRE accumulation with repeat dosing (Fig. 6).

Pharmacokinetics in Dogs. A marked difference in the plasma TRE PK profile was observed between inhaled TRE and the inhaled LNP TRE prodrugs (C16TR, C14TR, and C12TR) (Fig. 7). The highest plasma TRE was seen within a few minutes after inhalation of TRE and the TRE prodrugs and at a targeted inhaled dose of $18 \mu \mathrm{g} / \mathrm{kg}$, the plasma TRE $C_{\max }$ was highest with inhaled TRE ( $5.5 \mathrm{ng} / \mathrm{ml})$, slightly lower with inhaled C12TR-LNP $(1.2 \mathrm{ng} / \mathrm{ml})$ and 14-times lower with inhaled C14TR-LNP and C16TR-LNP $(0.4 \mathrm{ng} / \mathrm{ml})$ (Table 5). Furthermore, TRE was not detected in the plasma by 24 hours after inhaled TRE, but it was present at this time after inhalation with each of the TRE prodrugs (Fig. 7). The rank-order values for AUC $0-24 \mathrm{~h}$ at a targeted inhaled dose of $18 \mu \mathrm{g} / \mathrm{kg}$ was highest for inhaled TRE $(5.08 \mathrm{ng} * \mathrm{~h} / \mathrm{ml})$ and lower with inhaled C12TR-LNP $(4.20 \mathrm{ng} * \mathrm{~h} /$ $\mathrm{ml})$, inhaled C14TR-LNP (2.91 $\mathrm{ng} * \mathrm{~h} / \mathrm{ml})$, and inhaled C16TRLNP $(2.08 \mathrm{ng}$ h/ml $)$ (Table 5).
Inhaled C16TR-LNP produced dose-dependent increases in plasma TRE with levels of TRE detected up to 72 hours after inhalation for doses of 46 and $95 \mu \mathrm{g} / \mathrm{kg}$ (Fig. 8A). Corresponding values for plasma TRE $C_{\max }$ and AUC $0-24 \mathrm{~h} / 0-72 \mathrm{~h}$ also increased in a dose-dependent manner (Table 5). In contrast, plasma concentrations of TRE were highest immediately after inhalation of TRE ( 5 and $16 \mu \mathrm{g} / \mathrm{kg}$ ) but were below the limit of quantitation by 24 hours (Fig. 8B).

Inhaled TRE produced cough, rapid shallow breathing, emesis, and pale gums at a delivered pulmonary dose of $16 \mu \mathrm{g} / \mathrm{kg}$. Similar findings were observed with inhaled C12TRLNP at a delivered pulmonary dose of $19 \mu \mathrm{g} / \mathrm{kg}$ but not with inhaled C16TR-LNP and C14TR-LNP until higher delivered pulmonary doses (93-95 $\mu \mathrm{g} / \mathrm{kg}$ ) were given (Table 5).

Cough Reflex in Guinea Pigs. A preliminary evaluation with inhaled TRE demonstrated that a $30 \mu \mathrm{g} / \mathrm{ml}$ concentration could consistently evoke cough in all guinea pigs (seven of seven) tested. Lower concentrations of TRE $(1,3.3$, and $10 \mu \mathrm{g} / \mathrm{ml})$ did not consistently cause cough in each guinea pig and were therefore not deemed appropriate to compare the effect of inhaled C16TR-LNP. An additional guinea pig was administered TRE at $300 \mu \mathrm{g} / \mathrm{ml}$, but the exposure was discontinued as a result of adverse effects. PBS was also administered to six guinea pigs and did not induce cough.

The cough response to inhaled TRE was characterized by bouts of high-frequency cough with relatively low cough sounds. At a concentration of $30 \mu \mathrm{g} / \mathrm{ml}$, TRE consistently produced cough in all guinea pigs (mean, $36 \pm 9$ coughs; range, 17-82 coughs); coughing occurred with one to four bouts per guinea pig. In contrast, inhaled C16TR-LNP at a concentration of $47 \mu \mathrm{g} / \mathrm{ml}$ (C16TR molar concentration equivalent to $30 \mu \mathrm{g} / \mathrm{ml}$ of TRE) did not induce cough in any guinea pig (Fig. 9).

\section{Discussion}

Inhaled TRE is a pulmonary vasodilator used for the treatment of PAH. Although this compound has achieved some clinical success (Channick et al., 2012), it may not have reached its full potential because of its relatively short duration of action and the number of adverse side effects it evokes (Voswinckel et al., 2006; Nadler and Edelman, 2010; Channick et al., 2012). To improve the duration of action and reduce the side effects of TRE, LNP formulations of C16TR were developed, resulting in

TABLE 4

Plasma PK parameters for TRE in rats after once-daily administration of inhaled C16TR formulated in squalane/DSPEPEG2000 LNP for up to 14 consecutive days

Values are the mean $(n=4$ per dose).

\begin{tabular}{|c|c|c|c|c|c|c|c|c|}
\hline C16TR PD $(\mu \mathrm{g} / \mathrm{kg})$ & Group & IBD $(\mathrm{ng} / \mathrm{mL})$ & $C_{\max }(\mathrm{ng} / \mathrm{ml})$ & Average $C_{\max }(\mathrm{ng} / \mathrm{mL})$ & $\underset{\left(h^{*} n g / m L\right)}{\mathrm{AUC}_{0-24}}$ & $\underset{\left(h^{*} \text { Avg/mL) }\right.}{\text { Average } \text { AUC }_{0-24}}$ & AUC/PD & $\begin{array}{l}\text { Average } \\
\text { AUC/PD }\end{array}$ \\
\hline \multirow[t]{3}{*}{0.6} & Day 1 & NA & 0.14 & 0.22 & 0.44 & 1.10 & 0.73 & 1.83 \\
\hline & Day 7 & 0 & 0.23 & & 1.03 & & 1.72 & \\
\hline & Day 14 & 0.015 & 0.28 & & 1.83 & & 3.05 & \\
\hline \multirow[t]{3}{*}{1.8} & Day 1 & NA & 0.75 & 0.73 & 4.88 & 5.86 & 2.71 & 3.26 \\
\hline & Day 7 & 0.042 & 0.82 & & 7.89 & & 4.38 & \\
\hline & Day 14 & 0.069 & 0.63 & & 4.82 & & 2.68 & \\
\hline \multirow[t]{3}{*}{6} & Day 1 & NA & 0.72 & 1.66 & 4.15 & 11.15 & 0.69 & 1.86 \\
\hline & Day 7 & 0.042 & 2.79 & & 18.5 & & 3.09 & \\
\hline & Day 14 & 0.093 & 1.48 & & 10.8 & & 1.80 & \\
\hline \multirow[t]{3}{*}{18} & Day 1 & NA & 6.48 & 5.46 & 50.4 & 48.33 & 2.80 & 2.69 \\
\hline & Day 7 & 0.297 & 5.18 & & 48.0 & & 2.67 & \\
\hline & Day 14 & 0.190 & 4.71 & & 46.6 & & 2.59 & \\
\hline
\end{tabular}

IBD, Immediately before dose; NA, not applicable; PD, pulmonary dose. 


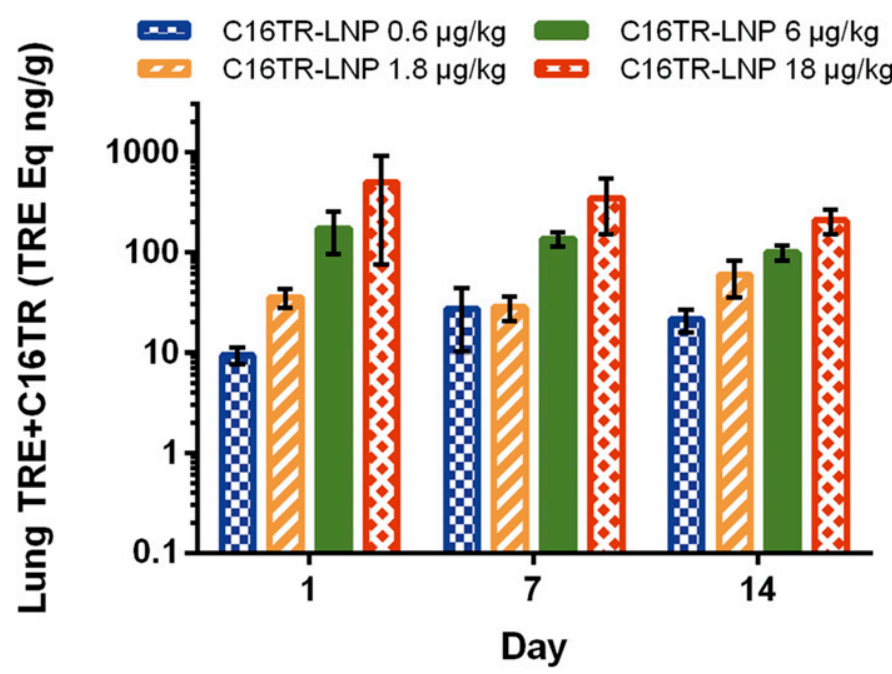

Fig. 6. Combined TRE + C16TR (TRE Eq) in the lungs after nose-only inhalation of C16TR formulated in squalane/DSPE-PEG2000 LNP for 1, 7, or 14 days in rats. Lung PK measurements were made 24 hours after the last dose. Values are the mean \pm S.E.M. $(n=4$ per dose $)$.

a lead compound, INS1009 (Leifer et al., 2017, unpublished). In this report, pharmacologic and PK studies were performed to highlight some of the important features of inhaled C16TRLNP. We found that C16TR possessed no inherent pharmacologic activity on prostanoid receptors and was weakly active in a rat platelet aggregation assay. Inhaled LNP formulations of C16TR produced long-acting pulmonary vasodilation in hypoxia-challenged rats, most likely owing to the slow conversion of TRE from C16TR present in the lungs. Lower plasma TRE $C_{\max }$ was found with inhaled C16TR-LNP compared with inhaled TRE in rats and dogs, and no evidence of drug accumulation was seen in the plasma and lungs with repeat dosing for 14 consecutive days in rats. Inhaled C16TR-LNP was well tolerated in rats, guinea pigs, and dogs, with a lower incidence of TRE-related side effects, such as cough, compared with inhaled TRE.

To establish whether C16TR can be classified as an inactive prodrug, evaluations were performed in receptor binding and enzyme inhibition assays, including studies on binding to prostanoid receptors $\left(\mathrm{DP}_{1}, \mathrm{IP}, \mathrm{EP}_{1}, \mathrm{EP}_{2}, \mathrm{EP}_{3}\right.$, and $\mathrm{EP}_{4}$ receptors) that are activated by TRE and involved with relaxation of pulmonary vascular smooth muscle (Walch et al., 1999; Foudi et al., 2008; Lai et al., 2008; Orie and Clapp, 2011; Whittle et al., 2012). We found that TRE bound to $\mathrm{DP}_{1}$, IP, $\mathrm{EP}_{1}, \mathrm{EP}_{2}$, and $\mathrm{EP}_{4}$ receptors with a rank-order potency similar to those previously described (Whittle et al., 2012). In these assays, $\mathrm{C} 16 \mathrm{TR}(10 \mu \mathrm{M})$ had no activity and also was inactive in a general battery of receptor binding and enzyme inhibition screens (data not shown). C16TR was weakly active in a platelet aggregation assay that previously demonstrated potent effects with TRE (Moncada et al., 1978; Whittle et al., 1978). These results demonstrate that C16TR possesses no inherent pharmacologic activity and are consistent with structure-activity data on the human prostacyclin receptor that identify the carboxy group at the $\mathrm{C} 1$ position as critical for ligand binding to the receptor (Stitham et al., 2003). In the synthesis of C16TR, the $\mathrm{C} 1$ position at the carboxy group is replaced with an ester bond that links the hexadecyl carbon chain to TRE (Leifer et al., 2014; 2017, unpublished).

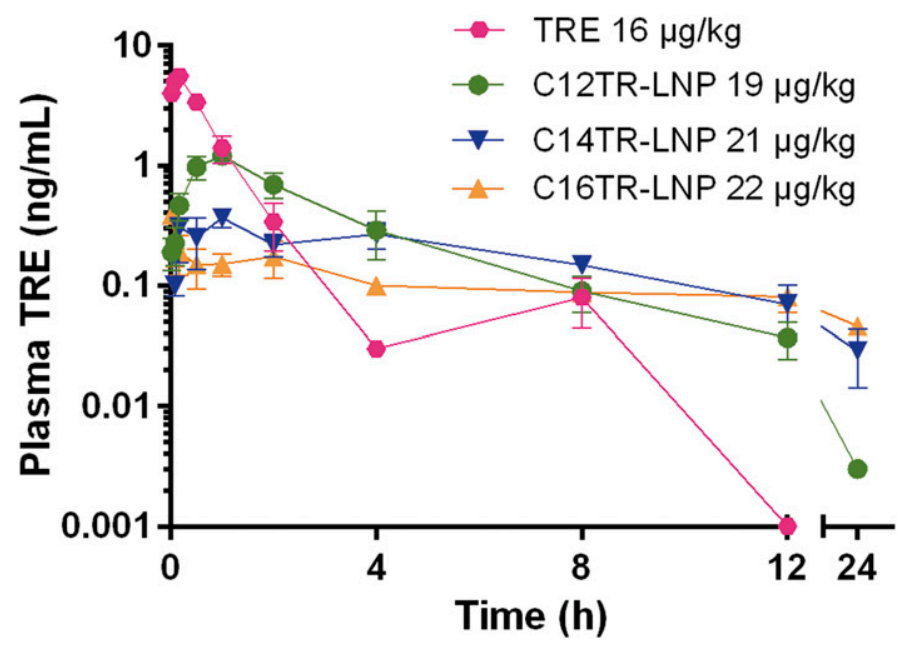

Fig. 7. Concentration of TRE in the plasma of dogs after inhaled TRE and the TRE prodrugs formulated in squalane/DOPC/cholesterol-PEG2000 LNP. The dogs were exposed to TRE $(16 \mu \mathrm{g} / \mathrm{kg}, n=5), \mathrm{C} 12 \mathrm{TR}-\mathrm{LNP}(19 \mu \mathrm{g} /$ $\mathrm{kg}, n=5)$, C14TR-LNP $(21 \mu \mathrm{g} / \mathrm{kg}, n=2)$, and C16TR-LNP $(22 \mu \mathrm{g} / \mathrm{kg}, n=5)$. Values are the mean \pm S.E.M.

When the prodrug C16TR is cleaved by lung esterases (Leifer et al., 2014, 2017, unpublished), it also produces hexadecanol, which is expected to be readily metabolized by pulmonary pneumocytes (Frenkel et al., 1993); note that hexadecanol was a constituent of the artificial pulmonary surfactant Exosurf (colfosceril palmitate) (Durand et al., 1985).

In vivo evaluations in hypoxia-exposed pulmonary hypertensive rats have identified several important features that distinguish inhaled C16TR-LNP from TRE. First, there was an immediate reduction in PAP after inhalation of TRE, whereas the reduction in PAP with inhaled C16TR took several minutes to develop. Second, the reductions in PAP persisted through 180 minutes after inhalation of C16TR-LNP but not with inhaled TRE. We have recently confirmed and extended our observations on the prolonged pulmonary vasodilator activity of C16TR-LNP in rats and dogs in which C16TR-LNP was delivered by nose-only inhalation, followed by challenge with U46619 and hypoxia to induce pulmonary vasoconstriction ( $\mathrm{Li}$ et al., 2016; Malinin et al., 2017). The results demonstrate an inhibition of pulmonary vasoconstriction up to 24 hours after a single inhaled dose of C16TR-LNP. The actions of C16TR-LNP producing pulmonary vasodilation are likely owing to the slow sustained release of TRE from C16TRLNP after cleavage of the ester bond by the actions of endogenous lung esterase(s). This conclusion is supported by data with C16OTR, an ether-linked C16TR compound that is unaffected by the enzymatic actions of endogenous esterase (Blaner et al., 1984) and showed no activity to inhibit hypoxiainduced pulmonary vasoconstriction in rats.

There were also important differences in the PK profile of inhaled C16TR-LNP and TRE. In the efficacy studies measuring reductions in PAP in hypoxia-challenged rats, plasma TRE $C_{\max }$ was approximately 16-fold higher after inhaled TRE compared with C16TR-LNP. In these studies, plasma TRE decreased over 3 hours after inhaled TRE but slowly increased after C16TR-LNP. In dogs, the plasma TRE $C_{\max }$ was 14-fold lower after C16TR-LNP $(18 \mu \mathrm{g} / \mathrm{kg})$ and sustained over 24 hours, whereas plasma TRE quickly disappeared after the same inhaled dose of TRE. In single-dose 
TABLE 5

Plasma PK of TRE and clinical signs in dogs after administration of inhaled TRE or inhaled C12TR, C14TR and C16TR formulated in squalane/DOPC/cholesterol-PEG2000 LNP

Values represent the mean values.

\begin{tabular}{|c|c|c|c|c|c|c|c|}
\hline Compound & $n$ & $\begin{array}{c}\text { Targeted } \\
\text { Pulmonary Dose }(\mu \mathrm{g} / \mathrm{kg})\end{array}$ & $\begin{array}{l}\text { Delivered Pulmonary } \\
\text { Dose }(\mu \mathrm{g} / \mathrm{kg})\end{array}$ & $\underset{(\mathrm{ng} / \mathrm{mL})}{C_{\max }}$ & $T_{\max }(\mathrm{h})$ & $\begin{array}{l}\mathrm{AUC}_{0-24 \mathrm{~h}} \\
\left(\mathrm{ng} \mathrm{h}^{*} \mathrm{~mL}\right)\end{array}$ & $\begin{array}{l}\mathrm{AUC}_{0-72 \mathrm{~h}} \\
(\mathrm{ng} * \mathrm{~h} / \mathrm{mL})\end{array}$ \\
\hline \multirow[t]{2}{*}{ TRE } & 3 & 6 & 5 & 2.7 & 0.1 & 1.71 & 1.71 \\
\hline & 5 & 18 & $16^{a}$ & 5.5 & 0.2 & 5.08 & 5.08 \\
\hline C12TR-LNP & 5 & 18 & $19^{a}$ & 1.2 & 1 & 4.20 & 4.98 \\
\hline \multirow[t]{2}{*}{ C14TR-LNP } & 2 & 18 & 21 & 0.4 & 1 & 2.91 & 4.44 \\
\hline & 3 & 95 & $93^{a}$ & 1.5 & 1 & 12.45 & 16.10 \\
\hline \multirow[t]{4}{*}{ C16TR-LNP } & 3 & 6 & 7 & 0.2 & 0.1 & 0.97 & 1.35 \\
\hline & 5 & 18 & 22 & 0.4 & 0.02 & 2.08 & 3.34 \\
\hline & 3 & 40 & 46 & 0.9 & 0.02 & 4.22 & 6.71 \\
\hline & 3 & 95 & $95^{a}$ & 1.5 & 0.1 & 11.67 & 18.98 \\
\hline
\end{tabular}

${ }^{a}$ Clinical signs of cough, rapid shallow breathing, emesis, and pale gums.

and 14-day repeat dose studies with C16TR-LNP in rats, dosedependent increases in plasma TRE $C_{\max }$ and AUC were found with no evidence of drug accumulation in the plasma or lungs with repeat dosing. TRE in the plasma and lungs was slowly eliminated after inhaled C16TR-LNP in rats with a first-order exponential decline over 24 hours. Similar results were found with shorter-chain TRE prodrugs in rats (C12TRLNP, C14TR-LNP) (Malinin et al., 2014). The slow elimination of TRE from the lungs has important implications for efficacy studies because a "localized" pulmonary vasodilator action of TRE in the lungs has been previously reported for continuously inhaled TRE in sheep (Sandifer et al., 2005) and more recently with inhaled C16TR-LNP in rats and dogs (Li et al., 2016; Malinin et al., 2017). A localized effect occurs when pulmonary vasodilation is observed, but plasma levels are below the levels necessary for injected (systemic) TRE to achieve pulmonary vasodilation. Because many of the adverse events correlate with plasma levels, the implications of reduced systemic exposure may be significant.

Cough is frequently seen with inhaled TRE in human subjects and limits the dose and the frequency of administration of this drug (Nadler and Edelman, 2010; Channick, et al., 2012). Pulmonary $C$ fibers are likely to be involved as they are activated by prostacyclin (Mapp et al., 1991; Ishiura et al., 2007) and are the same receptors involved with the cough response to another prostaglandin (i.e., prostaglandin $\mathrm{E}_{2}$ ) in guinea pigs (Maher et al., 2009; Maher and Belvisi, 2010). To test the hypothesis that reduced cough would be observed with C16TR-LNP, experiments were performed in guinea pigs, a species that duplicates many of the features of cough in humans (Morice et al., 2007; Canning, 2008; Maher et al., 2009). At a nebulized concentration of $30 \mu \mathrm{g} / \mathrm{ml}$, inhaled TRE produced a consistent cough response, whereas inhaled C16TR-LNP did not. Similar findings were recently found with C16TR-LNP delivered in a dry powder formulation that did not cause cough, whereas nebulized TRE at 10 and 30, but not at $3 \mu \mathrm{g} / \mathrm{ml}$, produced a consistent cough response (Chapman et al., 2017). It is important to note that TRE-related side effects in dogs, such as cough and rapid shallow breathing, were seen only at the highest inhaled dose $(95 \mu \mathrm{g} / \mathrm{kg})$ of C16TR.

A phase 1 study has been conducted in healthy volunteers to determine the safety, tolerability, and PK of escalating doses of C16TR-LNP relative to Tyvaso (Han et al., 2016 a,b). The results demonstrate that at the lowest dose of $85 \mu \mathrm{g}$, inhaled C16TR-LNP had a lower plasma TRE $C_{\max }$, sustained levels of TRE in the plasma over 12 hours with no incidence of cough, and throat irritation compared with inhaled Tyvaso $(54 \mu \mathrm{g})$. Higher doses of C16TR-LNP (170 and $340 \mu \mathrm{g}$ ) were well
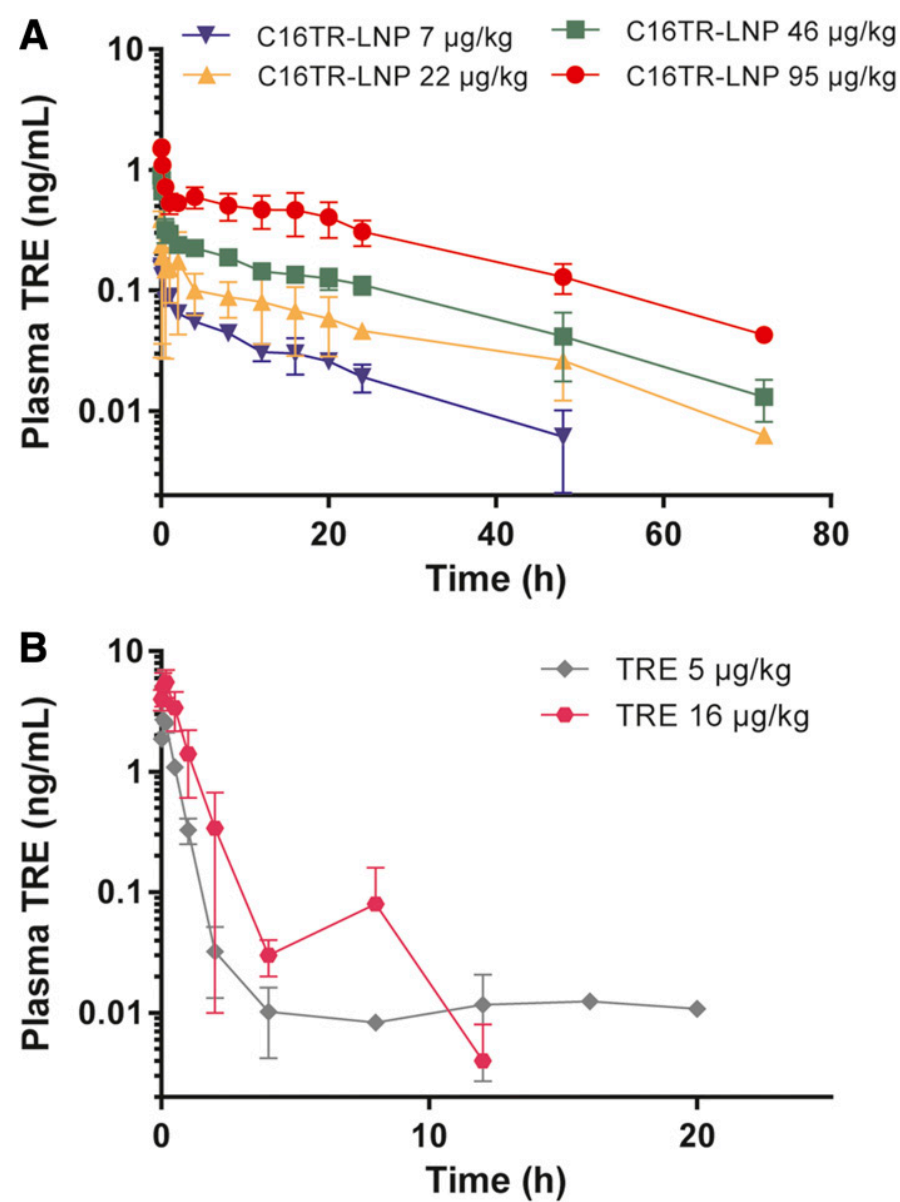

Fig. 8. Concentration of TRE in the plasma of dogs after inhaled (A) C16TR formulated in squalane/DOPC/cholesterol-PEG2000 LNP and (B) TRE. The dogs were exposed to TRE $(5, n=3$ and $16 \mu \mathrm{g} / \mathrm{kg}, n=5)$ or C16TR-LNP ( $7, n=3 ; 22, n=5 ; 46, n=3 ; 95 \mu \mathrm{g} / \mathrm{kg}, n=3)$, and blood samples were collected over 72 hours. Values are mean \pm S.E.M. 
A
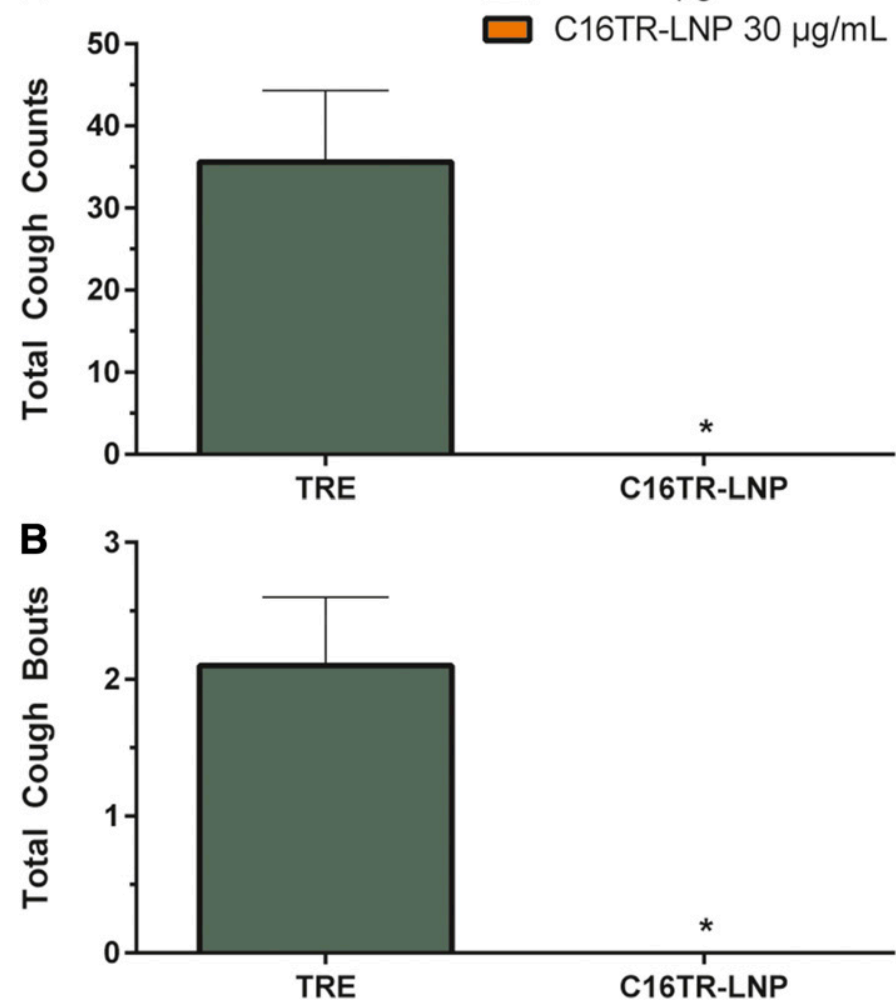

Fig. 9. Effect of inhaled TRE and C16TR formulated in squalane/DSPEPEG2000 LNP on cough in guinea pigs. The results are (A) the total number of coughs and (B) the number of cough bouts induced by inhaled TRE $(30 \mu \mathrm{g} / \mathrm{ml})$ and inhaled C16TR-LNP $(30 \mu \mathrm{g} / \mathrm{ml}$ TRE Eq). Values are the mean \pm S.E.M. for TRE $(n=7)$ and C16TR-LNP $(n=6)$. ${ }^{*} P<0.05$ compared with TRE

tolerated, and measurable levels of TRE were detected in the plasma up to 24 hours after single dose administration. Similar results were obtained in our preclinical studies with C16TR-LNP, which demonstrate sustained levels of TRE in the plasma over 12-24 hours in rats and dogs and no indication of cough in guinea pigs. These results demonstrate good translatability between the preclinical and clinical paradigms and based on other preclinical studies showing a prolonged "localized" pulmonary vasodilator effect in the lungs (Li et al., 2016; Malinin et al., 2017), we believe C16TR-LNP has the potential for once-daily, convenient dosing in humans.

In summary, these preclinical studies identify inhaled C16TR-LNP as a long-acting pulmonary vasodilator that involves the slow, sustained release of TRE from C16TRLNP. C16TR is devoid of inherent pharmacologic activity and had no direct effect to inhibit platelet aggregation. The PK properties of C16TR-LNP in rats and dogs with low plasma TRE $C_{\max }$ and sustained levels of TRE in the lungs support the concept of a "localized" effect in the lungs contributing to its prolonged pulmonary vasodilator activity. Inhaled C16TRLNP was well tolerated in rats, dogs, and guinea pigs, and there was no evidence of TRE accumulation in the blood and lungs after repeat dosing. Inhaled C16TR did not cause cough in guinea pigs. In conclusion, the attributes of inhaled C16TRLNP described herein offer an advantage over inhaled TRE with regard to a longer interval between dosing and a reduced potential for side effects.

\section{Authorship Contributions}

Participated in research design: Corboz, Li, Malinin, Perkins, Chapman.

Conducted experiments (platelet aggregation, hypoxia challenge in rats, $P K$ in rats): Laurent, Yin, Salvail.

Conducted experiments (cough reflex in guinea pigs, $P K$ in dogs): Zhuang, Xu, Curran.

Performed data analysis: Li, Chen, Laurent, Yin, Biernat, Zhuang, $\mathrm{Xu}$, Curran.

Contributed new reagents and analytic tools: Plaunt, Konicek, Leifer. Wrote or contributed to the writing of the manuscript: Corboz, Perkins, Chapman.

\section{References}

Abman SH (2009) Role of endothelin receptor antagonists in the treatment of pulmonary arterial hypertension. Annu Rev Med 60:13-23.

Alexander DJ, Collins CJ, Coombs DW, Gilkison IS, Hardy CJ, Healey G, Karantabias G, Johnson N, Karlsson A, Kilgour JD, et al. (2008) Association of Inhalation Toxicologists (AIT) working party recommendation for standard delivered dose calculation and expression in non-clinical aerosol inhalation toxicology studies with pharmaceuticals. Inhal Toxicol 20:1179-1189.

Blaner WS, Halperin G, Stein O, Stein Y, and Goodman DS (1984) Inhibition of rat liver retinyl palmitate hydrolase activity by ether analogs of cholesteryl esters and acylglycerides. Biochim Biophys Acta 794:428-434.

Canning BJ (2008) The cough reflex in animals: relevance to human cough research. Lung 186 (Suppl 1): S23-S28.

Channick RN, Voswinckel R, and Rubin LJ (2012) Inhaled treprostinil: a therapeutic review. Drug Des Devel Ther 6:19-28.

Chapman RW, Malinin V, Konicek D, Leifer F, Li Z, Zhuang J, Xu F, and Perkins WR (2015) Effect of a lipid nanoparticle prodrug formulation of treprostinil on the cough reflex in guinea pigs. Am J Respir Crit Care Med 191:A1952.

Chapman RW, Plaunt AJ, Gauani H, Corboz MR, Malinin VS, Perkins WR, Buote C, Laurent C-E, Salvail D, and Li Z (2017) Inhalation of dry powder INS1009 (DPINS1009) does not activate the cough reflex in guinea pigs: a comparison with nebulized treprostinil. Eur Resp J 2017; 50: Suppl. 61. Abstract \# 3048

Chow S-C and Liu J-P (2007) Design and Analysis of Bioavailability and Bioequivalence Studies, 3rd ed. Boca Raton, FL, Chapman \& Hall/CRC Biostatistics Series 9-14.

Dunn OJ (1961) Multiple comparisons among means. J Am Stat Assoc 56:52-64.

Durand DJ, Clyman RI, Heymann MA, Clements JA, Mauray F, Kitterman J, and Ballard P (1985) Effects of a protein-free, synthetic surfactant on survival and pulmonary function in preterm lambs. J Pediatr 107:775-780.

Feldman J, Im Y, and Gill K (2015) Oral treprostinil diethanolamine for pulmonary arterial hypertension. Expert Rev Clin Pharmacol 8:55-60.

Foudi N, Kotelevets L, Louedec L, Leséche G, Henin D, Chastre E, and Norel X (2008) Vasorelaxation induced by prostaglandin $\mathrm{E}_{2}$ in human pulmonary vein: role of the $\mathrm{EP}_{4}$ receptor subtype. Br J Pharmacol 154:1631-1639.

Frenkel RA, Narahara H, Eguchi H, Toyoshima K, and Johnston JM (1993) Metabolism of hexadecanol by rat type II pneumonocytes. Biochem Biophys Res Commun 196:885-891.

Frumkin LR (2012) The pharmacological treatment of pulmonary arterial hypertension. Pharmacol Rev 64:583-620.

Han D, Fernandez C, Sullivan E, Xu D, Perkins WR, Darwish M, and Rubino C (2016a) Single-dose pharmacokinetics of C16TR for inhalation (INS1009) vs treprostinil inhalation solution (Tyvaso®). Eur Respir J 48:2398.

Han D, Fernandez C, Sullivan E, Xu D, Perkins WR, Darwish M, and Rubino C (2016b) Safety and pharmacokinetics study of a single ascending dose of C16TR for inhalation (INS1009). Eur Respir J 48:2398.

Ishiura Y, Fujimura M, Nobata K, Oribe Y, Abo M, and Myou S (2007) Prostaglandin I2 enhances cough reflex sensitivity to capsaicin in the asthmatic airway. Cough 3:2

Khaybullina D, Patel A, and Zerilli T (2014) Riociguat (adempas): a novel agent for the treatment of pulmonary arterial hypertension and chronic thromboembolic pulmonary hypertension. $P \& T$ 39:749-758.

Kruskal W and Wallis WA (1952) Use of ranks in one-criterion variance analysis. $J$ Am Stat Assoc 47:583-621.

Kuehl PJ, Barrett EG, McDonald JD, Rudolph K, Vodak D, Dobry D, and Lyon D (2010) Formulation development and in vivo evaluation of a new dry powder formulation of albuterol sulphate in beagle dogs. Pharm Res 27:894-904.

Lai YJ, Pullamsetti SS, Dony E, Weissmann N, Butrous G, Banat GA, Ghofrani HA, Seeger W, Grimminger F, and Schermuly RT (2008) Role of the prostanoid EP4 receptor in iloprost-mediated vasodilatation in pulmonary hypertension. Am $J$ Respir Crit Care Med 178:188-196.

Leifer FG, Konicek DM, Chen K-J, Plaunt AJ, Salvail D, Laurent CE, Corboz MR, Li Z Chapman RW, Perkins WR, and Malinin VS (2017) Inhaled treprostinil-prodrug lipid nanoparticle formulations provide long-acting pulmonary vasodilation. (Unpublished manuscript).

Leifer FG, Omiatek DM, Malinin V, Ong J, Li Z, Klecha P, Chapman RW, Salvail D, Laurent C-E, and Perkins WR (2014) Prolonged activity of inhaled treprostinil prodrug nanoparticles in a rat model of pulmonary arterial hypertension. Eur Respir J 44:P2356. Li Z, Chapman RW, Malinin VS, Corboz MR, Plaunt AJ, Laurent CE, Yin H, Salvail D, and Perkins WR (2016) Inhaled INS1009 demonstrates localized pulmonary vasodilation. Eur Respir J 48:P2485.

Maher SA and Belvisi MG (2010) Prostanoids and the cough reflex. Lung 188 (Suppl 1):S9-S12.

Maher SA, Birrell MA, and Belvisi MG (2009) Prostaglandin E2 mediates cough via the EP3 receptor: implications for future disease therapy. Am J Respir Crit Care Med 180:923-928. 
Malinin V, Li Z, Chapman RW, Leifer F, Konicek D, Salvail D, Laurent C, Yin H, and Perkins WR (2015) A 14-day assessment of the tolerability and pharmacokinetics (PK) with a nanoparticle formulation of hexadecyl-treprostinil, a long-acting pulmonary vasodilator, in rats. Am J Respir Crit Care Med 191:A1948.

Malinin V, Li Z, Chapman RW, Leifer F, Omiatek D, Ong J, Salvail D, Laurent C-E, and Perkins WR (2014) Treprostinil pharmacokinetics in rats are extended using inhaled prodrug formulations. Eur Respir J 44:P2367.

Malinin VS, Plaunt A, Li Z, Gauani H, Corboz MR, Dziak C, Perkins WR, and Chapman RW (2017) INS1009, an inhaled hexadecyl treprostinil prodrug, demonstrates local pulmonary vasodilation activity in dogs. Am J Respir Crit Care Med 195:A8027.

Mapp CE, Fabbri LM, Boniotti A, and Maggi CA (1991) Prostacyclin activates tachykinin release from capsaicin-sensitive afferents in guinea-pig bronchi through a ruthenium red-sensitive pathway. Br J Pharmacol 104:49-52.

Moncada S, Vane JR, and Whittle BJR (1978) Relative potency of prostacyclin $\left(\mathrm{PGI}_{2}\right)$ prostaglandin $\mathrm{E}_{1}$ and prostaglandin $\mathrm{D}_{2}$ as inhibitors of platelet aggregation in several species. J Physiol 273:2P-4P.

Morice AH, Fontana GA, Belvisi MG, Birring SS, Chung KF, Dicpinigaitis PV, Kastelik JA, McGarvey LP, Smith JA, Tatar M, et al.; European Respiratory Society (ERS) (2007) ERS guidelines on the assessment of cough. Eur Respir $J$ 29:1256-1276.

Nadler ST and Edelman JD (2010) Inhaled treprostinil and pulmonary arterial hypertension. Vasc Health Risk Manag 6:1115-1124.

Orenitram (treprostinil). (2014) Package insert. United Therapeutics Corporation, Research Triangle Park, NC.

Orie NN and Clapp LH (2011) Role of prostanoid IP and EP receptors in mediating vasorelaxant responses to PGI2 analogues in rat tail artery: evidence for $\mathrm{Gi} / \mathrm{o}$ modulation via EP3 receptors. Eur J Pharmacol 654:258-265.

Remodulin (treprostinil). (2014) Package insert. United Therapeutics Corporation, Research Triangle Park, NC.

Sandifer BL, Brigham KL, Lawrence EC, Mottola D, Cuppels C, and Parker RE (2005) Potent effects of aerosol compared with intravenous treprostinil on the pulmonary circulation. J Appl Physiol (1985) 99:2363-2368.

Simonneau G, Barst RJ, Galie N, Naeije R, Rich S, Bourge RC, Keogh A, Oudiz R, Frost A, Blackburn SD, et al. Treprostinil Study Group (2002) Continuous subcutaneous infusion of treprostinil, a prostacyclin analogue, in patients with pulmonary arterial hypertension: a double-blind, randomized, placebo-controlled trial. Am $J$ Respir Crit Care Med 165:800-804.
Skoro-Sajer N, Bonderman D, Wiesbauer F, Harja E, Jakowitsch J, Klepetko W, Kneussl MP, and Lang IM (2007) Treprostinil for severe inoperable chronic thromboembolic pulmonary hypertension. J Thromb Haemost 5:483-489.

Stamm JA, Risbano MG, and Mathier MA (2011) Overview of current therapeutic approaches for pulmonary hypertension. Pulm Circ 1:138-159.

Stitham J, Stojanovic A, Merenick BL, O'Hara KA, and Hwa J (2003) The unique ligand-binding pocket for the human prostacyclin receptor: site-directed mutagenesis and molecular modeling. J Biol Chem 278:4250-4257.

Taichman DB, Ornelas J, Chung L, Klinger JR, Lewis S, Mandel J, Palevsky HI, Rich S, Sood N, Rosenzweig EB, et al. (2014) Pharmacologic therapy for pulmonary arterial hypertension in adults: CHEST guideline and expert panel report. Chest 146:449-475.

Tyvaso (treprostinil). (2013) Package insert. United Therapeutics Corporation, Research Triangle Park, NC.

Voswinckel R, Enke B, Reichenberger F, Kohstall M, Kreckel A, Krick S, Gall H, Gessler T, Schmehl T, Ghofrani HA, et al. (2006) Favorable effects of inhaled treprostinil in severe pulmonary hypertension: results from randomized controlled pilot studies. J Am Coll Cardiol 48:1672-1681.

Walch L, Labat C, Gascard J-P, de Montpreville V, Brink C, and Norel X (1999) Prostanoid receptors involved in the relaxation of human pulmonary vessels. $\mathrm{Br} J$ Pharmacol 126:859-866.

Whittle BJ, Moncada S, and Vane JR (1978) Comparison of the effects of prostacyclin (PGI2), prostaglandin E1 and D2 on platelet aggregation in different species. Prostaglandins 16:373-388.

Whittle BJ, Silverstein AM, Mottola DM, and Clapp LH (2012) Binding and activity of the prostacyclin receptor (IP) agonists, treprostinil and iloprost, at human prostanoid receptors: treprostinil is a potent $\mathrm{DP}_{1}$ and $\mathrm{EP}_{2}$ agonist. Biochem Pharmacol 84:68-75.

Wilkins MR, Wharton J, Grimminger F, and Ghofrani HA (2008) Phosphodiesterase inhibitors for the treatment of pulmonary hypertension. Eur Respir $J$ 32:198-209.

Wolff RK and Dorato MA (1993) Toxicologic testing of inhaled pharmaceutical aerosols. Crit Rev Toxicol 23:343-369.

Address correspondence to: Michel R. Corboz, Insmed Incorporated, 10 Finderne Avenue, Building 10, Bridgewater, NJ 08807. E-mail: michel. corboz@insmed.com 